\title{
El paisaje en la literatura francesa a partir del siglo XIX y sus relaciones con la pintura
}

\section{The Landscape in French Literature since the Nineteenth Century and its relationship with painting}

\author{
Brigitte Leguen*
}

\begin{abstract}
«La terre est, comme notre peau, condamnée à conserver la trace des blessures anciennes»

(F. Braudel).
\end{abstract}

\section{APROXIMACIONES}

A partir del siglo xix, el paisaje cobra otros significados y la escritura se dramatiza. Los británicos nos hacen descubrir los amplios horizontes y el paisajismo, los alemanes aportan la nocturnidad y el sueño, los franceses el sentido trágico de la Historia y la crítica de las formas.

La contemplación del paisaje, su compleja traslación a las artes plásticas y a la literatura, nos obliga a interrogarnos sobre nuestra propia realidad interna y externa y sobre la relación que establecemos con nuestro entorno.

¿Qué entendemos por «paisaje» y cuál es su realidad y su ficción? ¿Cuál es el vínculo entre lo que el escritor Francisco Ayala denomina la «relación entre la obra del espíritu y su base de experiencia fáctica»? Es, en primer lugar y desde una primera aproximación, lo que puede ve el ojo humano, la configuración geográfica, los relieves, los mares, las costas, las montañas, siempre en

\footnotetext{
*Facultad de Filología, Universidad Nacional de Educación a Distancia (bleguen@flog.uned.es).
} 
función de quién observa, de lo que sabe, de lo que busca, y de cómo lo formula y a qué fines. El artista, el pintor, el escritor o el poeta seleccionan su visión y eligen las apariencias que mejor les convienen para expresarse. Los lugares, paisajes naturales o paisajes urbanos, son a menudo pretextos para manifestar simbólicamente emociones y sentimientos que poco tienen que ver (por no decir nada) con la mera materialidad del entorno. La creación artística en sus diversas manifestaciones plásticas o literarias da preferencia y relevancia a determinados paisajes dependiendo del gusto de una época determinada para fines determinados; por este motivo, el descubrimiento del valor artístico del paisaje urbano, las ciudades, los pueblos, las casas y edificios, los monumentos, las fábricas, acontece en pleno auge del desarrollo industrial y va unido a una determinada ideología y a una renovada conciencia del ser con su entorno.

La clasificación de los paisajes y su valoración tienen un valor histórico y relativo que nos puede llamar la atención desde un punto de vista sociológico pero sin perder de vista nunca que el arte inventa los paisajes y los carga de sentido, tanto si se trata de paisajes naturales, salvajes, no tocados por la mano del hombre, frutos de la naturaleza salvaje o virgen y de su evolución y erosión, como si abarca paisajes fabricados por el hombre, campos cultivados, árboles plantados, espacios acotados...

La etimología de la palabra es muy significativa y reveladora en su evolución. Los vocablos franceses pays, paysage, paysan proceden de pagensis y pagus. Recordemos que en francés el vocablo pays se utilizaba para hablar de un territorio rural de tamaño reducido y también para designar a una persona que pertenece al mismo pueblo (este vocablo ha quedado muy envejecido en francés y ya no se utiliza de forma habitual).

Por otro parte, el Diccionario de la Real Academia nos propone dos definiciones del término «paisaje»: por un lado es «una pintura o dibujo que representa cierta extensión de terreno» y es también «una porción de terreno considerado en su aspecto artístico».

$\mathrm{Al}$ referirnos al paisaje tenemos además que preguntarnos por el hombre y por su relación y protagonismo, sea porque está representado dentro del cuadro, sea porque contempla el cuadro y es entonces un espectador privilegiado que observa y contempla.

Al centrarnos, en este artículo, en los siglos XIX y xx no nos detendremos en el paisaje perfecto imaginado a lo largo de la tradición clásica, el locus amoenus con su marco convencional — cuyas características destacó Ernst Robert Curtius. El gran historiador del arte Ernst Gombrich fecha la conquista de la realidad ya por el siglo XV y se apoya en el cuadro de Conrad Witz titu- 
lado La pesca milagrosa, como prueba de la primera representación exacta, el primer «retrato» de un paraje auténtico ${ }^{1}$. A continuación, en su capítulo titulado «El espejo de la naturaleza» afirma que los holandeses son los primeros en la historia del arte en descubrir la belleza de los cielos, en particular gracias a la obra de Jacob van Ruisdael (1628?-1682) como pintor de paisajes con sus nubes, atardeceres y bosques frondosos. Sin embargo reconoce que el gran cambio en el arte acontece con la época de la gran Revolución cuando los artistas rompen con la tradición y consideran el arte como un medio de «expresión» siguiendo los pasos del famoso pintor Eugène Delacroix (1798-1863), que será la figura más revolucionaria del panorama artístico francés. Nos dice Gombrich refiriéndose al pintor francés que «consideró que, en la pintura, el color era mucho más importante que el dibujo, y la imaginación que la inteligencia» ${ }^{2}$, coincidiendo en esta apreciación con Charles Baudelaire tal y como consta en sus Salons. Delacroix capta el momento, el movimiento, la intensidad, la emoción y se detiene en esta inmediatez imparable de la modernidad cultivada luego en la fotografía y el reportaje. Es interesante detenerse en esta cuestión de la rapidez y de la inmediatez, que marca luego la cadencia de la postmodernidad ya que gran parte de los cambios que experimentamos actualmente tienen mucho que ver con el ritmo no solamente en cuestiones musicales sino también en las secuencias de cine.

El paisaje del XIX en pintura recoge momentos sencillos y cotidianos, alejados de la nobleza y de la mitología: Las espigadoras, de François Millet, son un claro ejemplo de esta nueva manera de mirar y de trasmitir una escena campestre. En aquel mismo momento, dentro del paisaje urbano (este «otro» paisaje tan presente a partir del inicio de la sociedad industrial) dominan las estructuras modernas y la potencia de los nuevos materiales empleados en la construcción de edificios - metal y cristal, sobre todo- como en La gare St Lazare de Monet.

Pero todo no es visible en el paisaje puesto que depende esencialmente de la mirada del hombre, de su contemplación, sensación, narración, y forma parte de un conjunto y de una relación, hombre/espacio, creador/espacio: el hombre ve y siente, pinta, escribe, asociando y elaborando un pensamiento en torno a su contemplación. A la configuración geográfica se superpone pues la

\footnotetext{
1 «Witz pintó verdaderos pescadores; no los sublimados apóstoles de los cuadros antiguos, sino toscos hombres del pueblo» (Gombrich, 1989, p. 180).

2 Delacroix se cansó de los temas cultos de la Academia y se fue a África del Norte en 1832 para estudiar los ornamentos del mundo árabe. Esta fascinación está compartida por los escritores del momento.
} 
configuración social y simbólica, lo que produce finalmente una polisemia del paisaje. Inevitablemente, el hombre asocia su existencia a su entorno y proyecta sus vivencias haciendo que los valores escondidos del paisaje sean también los valores escondidos del hombre. Cuando este hombre sube a una montaña, contempla un lago, un campo cultivado o yermo, cruza un desierto o se asoma desde un edificio muy alto, o por el contrario, se adentra en una cueva muy profunda, cambia de punto de vista y de actitud vital y de alguna manera hace suyo el espacio saliéndose de la percepción objetiva y puramente racional e integrando a su imaginario una realidad física para convertirla en una realidad imaginaria.

La pintura de finales del XIX, antes del gran paso a la abstracción, propone paisajes desdibujados como el de Cézanne Montañas de Provenza (1886), que pone en evidencia el sentido de la solidez y del volumen, o el Campo de trigo con cipreses de Van Gogh (1889), cercano a las estampas coloreadas japonesas que tanto admiraba el pintor. La gran dificultad para el estudioso está en el carácter sumamente individual del arte a partir de la Revolución. La abstracción no tiene una sola fecha, el cubismo no es la radical abolición de la representación, el arte sigue experimentando con libertad, al igual que la literatura, de allí también su increíble riqueza junto a su impredecible destino. Tanto Gombrich como Quentin Bell reconocen lo difícil que resulta acertar acerca de lo que hará o no historia, ante tal abundancia, y tal libertad de creatividad.

Conviene puntualizar, haciéndonos eco de las opiniones de reconocidos especialistas como Nicolás Ortega Cantero, que este nexo entre hombre y paisaje, al que nos acabamos de referir, no concierne solamente al individuo; es además social y colectivo.

Siguiendo este camino y abriendo un nuevo campo de investigación, Gaston Bachelard establece una "poética del espacio» en la que analiza precisamente el fenómeno de la imagen poética; el psicoanálisis, en particular la rama representada por C. G. Jung centrándose en el inconsciente colectivo basado en arquetipos o símbolos primordiales, recoge este mismo planteamiento.

Tanto para Bachelard como para el psicoanalista Jung la consciencia es en alguna medida el círculo menor dentro del círculo mayor de lo inconsciente.

Estas obras de gran alcance son una prueba de la necesidad de desvelamiento o de revelación, de lo visible y material. El espacio obviamente es un lugar de metáfora y detrás de su realidad está la otra más rica y diversa. La relación entre campo cultivado y fertilidad, campo yermo y esterilidad, frío y muerte, ascensión a los lugares elevados y bajada a los infiernos, asociados a los valores espirituales y místicos, está presente en la literatura y nos sitúa en el plano subjetivo de la realidad espacial. 
Por otra parte, la literatura, ya lo sabemos, es una fábrica de mundos. Asume los aspectos psicológicos del comportamiento humano, la peculiaridad de la percepción, la polisemia de lo visible y de lo invisible.

Si entendemos por literatura todo lo escrito por el hombre, nos podemos remontar a los textos sagrados para afirmar que desde el principio del relato escrito la realidad es un pretexto para la otra realidad, tanto como lo es el sueño en relación con el estado de vigilia.

\section{CORRESPONDENCIAS: LOS ESPACIOS REALES Y LOS ESPACIOS IMAGINARIOS}

Durante todo el siglo XIX, el interés por el paisaje es inmenso. La relación que los escritores establecen con el paisaje (este ente visible/invisible) es considerable y es equiparable al interés puesto por los pintores en el mismo momento. El Romanticismo es el gran responsable de las nuevas actitudes estéticas, pero ya durante el XVIII, con Montesquieu, después de Buffon, se difunde la teoría de los climas en la que se expone y justifica una relación entre el clima y la personalidad de los seres humanos, lo que influirá indirectamente en esta relación entre paisaje y personaje. Como bien sabemos, Montesquieu divide los tipos humanos en dos grandes grupos pertenecientes a los países del Norte y los del Sur.

Esta teoría no es nueva y ya desde Hipócrates se sostenía que el clima influía en el estado físico y mental del ser humano.

Esta argumentación de tipo ambientalista, renovada y adaptada a los nuevos tiempos por los filósofos de las Luces, tendrá un papel muy importante en el pensamiento de todo el siglo xix empezando por los románticos, que no eran amigos de la Ilustración pero sí de las correspondencias entre la naturaleza y el espíritu del hombre, este Bateau ivre y errante por el mundo.

Si nos centramos en Montesquieu debemos reconocer que su discurso no es completamente innovador pero sí sugerente: pone en relación las leyes y su adecuación con la diversidad de cultura y temperamento (v. Del espiritu de las leyes. lib. XIV, cap. II). Allí describe una máquina sana y bien constituida en los países del Norte, y en los del Sur un decaimiento moral creciente y un individualismo contrario al espíritu de empresa. Dicho prejuicio está por otra parte constantemente cuestionado si recordamos la fascinación de toda Europa, empezando por Francia, por el imaginario del Sur hasta el punto de mezclar en un mismo lugar Italia, España y el orientalismo a menudo equivocado y anacrónico que con tantas bellezas ha dotado la poesía, el teatro y la pintura francesa del romanticismo y del simbolismo. 
El tema de la causalidad climática es interesante, no tanto por sus soluciones que carecen de fundamento científico en muchos casos, sino porque pone en paralelo circunstancias que nos acercan a un tema muy recurrente: la interrelación entre el hombre y su medio. Voltaire y Volney estaban en contra de esta teoría de los climas y pensaban que primaban las instituciones y la correcta elección de gobiernos y de leyes.

Madame de Staël en cambio defiende esta postura y la amplia, apoyándose en la cultura alemana que conoce bien (v. Legen, 2002).

En Europa, durante el siglo XVIII, a finales, gracias a los grandes viajeros y a los relatos ficticios, se descubren paisajes que solamente existían en los sueños y que van a enriquecer enormemente el imaginario hasta el advenimiento de las Vanguardias. El geólogo suizo Horace Bénédicte de Saussure publica sus Voyages dans les Alpes en 1779. El primer aerostato que permitirá tener una visión desde arriba, desde el aire, despega cuatro años más tarde. Los arqueólogos exhuman en 1860 los restos de la ciudad de Pompeya, sepultada a consecuencia de la erupción del Vesuvio un siglo antes de Cristo.

Paralelamente en Europa nace la psiquiatría, que desemboca hacia 1900 en el descubrimiento del psicoanálisis, que lleva a explorar el nuevo continente del inconsciente y a emprender un nuevo viaje hacia dentro que se yuxtapone en muchas ocasiones al viaje de los escritores y héroes románticos conscientes de la relación entre el mundo mental y el mundo físico que les rodea, y al viaje utópico ya de moda con anterioridad.

Las profundidades del alma humana entran en correspondencia con los relieves del paisaje real. Los cambios de la naturaleza comulgan con la ciclotimia del alma. Una nueva simbiosis permite el encuentro entre el microcosmos y el macrocosmos. El alma tiene sus abismos y sus lejanías. No perdamos de vista que siempre estuvo presente este movimiento (recordemos a san Juan de la Cruz y su poesía mística), pero la búsqueda moderna se libera de la fe y entra en contacto con las apariencias sin la mediación de un dios. Lo expresa magníficamente Octavio Paz en su discurso a la Academia Sueca:

«Por primera vez en la historia, los hombres viven en una suerte de intemperie espiritual y no, como antes, a la sombra de esos sistemas religiosos y políticos que, simultáneamente, nos reprimían y nos consolaban. Las sociedades son históricas pero todas han vivido guiadas e inspiradas por un conjunto de creencias e ideas metahistóricas. La nuestra es la primera que se apresta a vivir sin una doctrina metahistórica; nuestros absolutos —religiosos o filosóficos, éticos o estéticos- no son colectivos sino privados. La experiencia es arriesgada. Es imposible saber si las tensiones y conflictos de esta privatización de ideas, prácticas y creencias que tradicionalmente pertenecían a la vida pública no terminara por quebrantar la fábrica 
social [ ... y concluye:] pero los poetas saben algo: el presente es el manantial de las presencias» ( $\mathrm{Paz}, 1990)$.

Xavier de Maistre publica en 1795 Voyage autour de ma chambre; Freud lee el libro de De Maistre y es conocido su gusto por la geografía, la geología y la arqueología. Poco a poco se construye la metáfora del «yo» como mundo. Parece que ya no quedan territorios vírgenes por descubrir; es, al menos, el sentir de James Cook después de sus descubrimientos en el océano Pacífico, entre 1774 y 1785 . Pero los límites del espacio real abren las puertas sin límite del espacio soñado.

Durante dos mil años los geógrafos apostaron por la existencia de una tierra austral llamada Tierra de las Antípodas, que posiblemente ocupase un cuarto de la superficie del globo terráqueo. Se demostró, gracias a las expediciones de Cook, que existían una sucesión de islas y con él se agotaron en parte los grandes sueños de conquista de las térrea incognitae.

Germaine de Staël, una mujer muy atenta a los cambios de sus época, afirma en una novela de 1807 titulada Corinne ou l'Italie que los descubrimientos y progresos hacia el conocimiento del espacio exterior incitan a los descubrimientos del espacio interior. Ella también insiste en el fin de los grandes descubrimientos pero proclama que el hombre tiene todavía que conquistar su propio yo que sigue siendo su mayor misterio. De Staël pone en paralelo la vastedad de la naturaleza con la vastedad del espíritu humano, alentada por su conocimiento del Romanticismo alemán y por una singular capacidad de análisis.

Otro personaje significativo y entendido es el científico, pintor, naturalista y médico Carl Gustav Carus, discípulo y amigo de Goethe con el que mantiene una interesante correspondencia; Carus establece con claridad en sus cartas la estrecha relación entre arte, estética y ciencia, y sobre todo la relación entre el hombre y la naturaleza.

Sus interesantísimas Cartas sobre pintura de paisaje beben de diversas fuentes, como son la filosofía de la naturaleza de Schelling, la influencia de pintores como Johann Christian Klengel (1751-1824), pintor de la escuela de Dresde, Salomon Gessner o Caspar David Friedrich con el que entabla una amistad provechosa. Junto al pintor entiende cómo se impone la subjetividad en la imitación pero sin desestimar el valor de la representación ${ }^{3}$.

\footnotetext{
3 Son numerosos los estudios sobre la cuestión de la mímesis y la problemática de la representación. He recogido indirectamente aquí los trabajos de Erich Auerbach y del francés Philippe Hamon.
} 
El género de paisaje, considerado como menor, ha ocupado un lugar indeciso en los tratados de pintura y sin embargo la tradición del paisaje se remonta a los orígenes de la pintura. A partir del siglo XVIII cobra mayor notoriedad como se puede apreciar en la importancia otorgada al legado de la pintura de Claudio Lorena, gran maestro de los maestros del XIX junto a los holandeses y base del paisajismo del Romanticismo como ya se comentó en la introducción.

El paisaje estaba considerado como un género de poca categoría y muy pocos tratadistas lo tomaban en serio. Lo hace Gérard de Lairesse, autor en 1707 de un estudio titulado El gran libro del pintor, pero la discusión sobre el rango que ocupa la pintura de paisaje hizo correr mucha tinta y muchos trataron con cierto desprecio esta petite manière que carece de heroicidad y que abusa del «sentimiento».

El paisaje galante de la escuela francesa, el capriccio veneciano o romano favorecen la interpretación sensualista que se opone al arte racionalista y moralizador de los clasicistas, considerado como el más fiable.

El paisaje es también a partir del XVIII un elemento propicio para la crítica de la nueva sociedad urbana. Es el contrapunto que opone la idílica experiencia de la vida en el campo frente a la decadencia de las grandes urbes, una crítica muy presente en la obra de Jean-Jacques Rousseau, padre del primer romanticismo francés. Este autor insiste en el efecto ético del paisaje sobre el paseante solitario, le promeneur solitaire, y en la suma importancia de la contemplación de la naturaleza para alcanzar la plenitud del ser. Los paisajes de montaña y su situación elevada son particularmente propicios para el enaltecimiento del alma del contemplador.

Los protestantes y los teólogos pietistas de finales del siglo XVIII consideraban la naturaleza como templo de la divinidad y asumieron un enfoque panteísta que influirá considerablemente en la estética prerromántica y en ideología prerrevolucionaria.

Junto a la visión ética del paisaje mediador de las emociones está también su ejecución técnica. Alexander Cozens publica en Londres un método titulado Nuevo método para asesorar a la inventiva al dibujar composiciones paisajísticas originales en el que inicia un estudio de las diversas técnicas a emplear: Parte de ejemplos muy básicos para paulatinamente aproximarse a la representación del paisaje. J. Constable y otros grandes pintores de paisajes aprovecharon sus clasificaciones.

En Francia, Pierre-Henri Valenciennes, unos años más tarde, redactó los Elementos de perspectiva práctica según procedimientos y clasificaciones muy parecidos. 
Alexander von Humboldt, autor de Cuadros de la naturaleza, alude también a la poderosa relación entre las emociones que experimenta el hombre y la naturaleza que las provoca, elevándole. El suizo Carus, gran seguidor de Claude Lorena, insiste en que se trata de un género preeminente moderno en el que domina lo visual y lo pictórico y se inspira para desarrollar esta teoría en el brillante ensayo de Herder (1778) titulado Plastik.

Resulta muy interesante poner en paralelo lo que comenta el francés Chateaubriand y lo que propone Carus al hablar de la fisonomía de las montañas, poniendo en relación las configuraciones de las rocas y de las nubes con el simbolismo de la figura humana. Chateaubriand propone igualmente hacer el «retrato» de la naturaleza del mismo modo que se retrata a un modelo humano.

Ya no se busca dar a ver una naturaleza a la medida del hombre sino una naturaleza sublime, imponente e incluso inhóspita y terrible. La violencia de los elementos naturales y su desorden aparente abren nuevas vías a los desórdenes de la mente (el personaje de Adolphe es un buen ejemplo de esta nueva modalidad).

Las ciencias humanas progresan mientras tanto y su reconocimiento favorece su difusión mediante la enseñanza. Kant enseña Geografía en Berlín y allí se crea la primera cátedra en esta materia. La geografía se extiende a otros territorios del intelecto. La psicología, la psiquiatría en particular, los escritores y filósofos ponen su atención en la ambivalente visión de una cartografía que abarca a su vez la del espíritu humano.

La subjetividad y la individualidad se manifiestan en los diarios íntimos que florecen en Francia: Jean-Jacques Rousseau llama amour de soi a la individualidad con el fin de distinguirlo del amour-propre. Este concepto implica una búsqueda del individuo que tiene que descubrir en soledad su propia felicidad, dándole preferencia a su singular punto de vista por encima de las reglas establecidas para todos.

La introspección gana terreno y talento. Stendhal y Benjamin Constant son los grandes maestros del «yo» de ficción. Adolphe, y La cartuja de Parma serán en la literatura francesa del siglo XIX una prueba fehaciente de esta nueva habilidad.

Para mostrar las almas, la ciencia y la literatura añaden imágenes a las palabras. Georges Rodenbach publica Bruges-la-Morte, en 1892, con fotos y Breton hará los mismo con Nadja. Los contemporáneos no han dejado de emplear este procedimiento hasta el momento (recordemos a Hervé Guibert o a Annie Ernaux o incluso a Patrick Modiano).

La huella, la trace, es uno de los aspectos de la modernidad. La escritura busca lo desconocido, la exploración de sensaciones hasta entonces calladas. 
Germaine de Staël en su libro De la Littérature ya insistía en el hecho de que la literatura está para puiser au fond de l'âme.

En su Journal de Jérusalem Chateaubriand reflexiona sobre la memoria y la contemplación del paisaje en diversos lugares del mundo y en diversos momentos de su vida. El escritor crea una realidad singular fuera de la cronología y de la geografía real, saltando de un tiempo a otro y de un espacio a otro, unidos en el río de una misma memoria, dice:

« Mais les moindres sentiments de mon enfance me sont présents, tout les retrace à mon cœur. Aux bords si solitaires des grands lacs de l'Amérique, je faisais, en voyant quelques hirondelles, les mêmes réflexions que je fais aujourd'hui sur les mers de la Syrie; je trouvais, dans une terre vide de souvenirs et qui n'a pour elle que sa solitude, les mêmes sentiments que j'éprouve presqu'à la vue des côtes de Chypre, de l'Egypte et de la Palestine, si fécondes en souvenirs et en sentiments. C'est que l'homme ne peut changer le fond de son cœur et que c'est là qu'il tire toute son existence. Les objets extérieurs peuvent le distraire un moment, mais ce qui l'occupera sans cesse, ce qui se présentera sans cesse à lui, c'est son intérieur, ce sont les rêveries accoutumées de son âme. Après avoir été errant quelques moments hors de lui-même, il retombe, et rentre pour ainsi dire dans son cœur, centre de son existence, de ses sentiments et de ses pensées " (Chateaubriand, 1947, p. 8).

Este texto, escrito desde la literatura, se sitúa exactamente en una actitud similar a la del pintor romántico ante el paisaje. Inician los dos - escritor y pintor - un nuevo diálogo con la naturaleza contemplada; la interiorizan y superponen a la visión real del mar, de la montaña, del arroyo que corre por la pradera, una dimensión simbólica y panteísta. El papel de la memoria es el lazo de unión entre los tiempos y los espacios. Se busca la interiorización de los sentimientos y las emociones desde diversos momentos y desde diversos lugares para crear una realidad plural y fragmentada.

Este nuevo diálogo responde también a un nuevo egotismo que desemboca en la adopción de una postura relativista por parte del sujeto contemplador. Los puntos de vistas cambian y se geometrizan las relaciones con el mundo: mundo visto desde la ventana, o desde una torre como el campanario de Grianta en la Chartreuse, o desde los barrotes de la cárcel de Farnese en la misma novela. Se ha hablado mucho de la escena de la batalla de Waterloo, captada desde la mirada de Fabrice al galope, en pleno movimiento, negando la enunciación estática:

« Tout à coup on partit au grand galop. Quelques instants après, Fabrice vit, à vingt pas en avant, une terre labourée qui était remuée d'une façon singulière. Le 
fond des sillons était plein d'eau, et la terre fort humide, qui formait la crête de ces sillons, volait en petits fragments noirs lancés à trois ou quatre pieds de haut. Fabrice remarqua en passant cet effet singulier ; puis sa pensée se remit à songer à la gloire du maréchal. Il entendit un cri sec auprès de lui : c'était deux hussarts qui tombaients atteints par des boulets ; et lorsqu'il les regarda, ils étaient déjà à vingt pas de l'escorte... » (Stendhal, 1965, p. 76).

Esta descripción está basada en los efectos cinéticos y la captación de todos los signos de la escena de batalla: tierra salpicada, humo, agua, polvo, lodo, velocidad. Sucesión de imágenes amenazadas por el movimiento y la precariedad de la mirada que capta al vuelo la escena. Esta nostalgia de la imagen en movimiento es imparable y lo encontramos muy frecuentemente, aunque no siempre con tanta maestría, en las novelas de este período. Destacaré también el magnífico travelling aeropanorámico (la fórmula es de Julien Gracq) de Balzac en la novela Les chouans.

Otra manera de relativizar el ángulo de la «realidad» es la utilización de la ventana, el cristal que separa el exterior (paisaje) del interior refugio, como en el poema de Baudelaire titulado precisamente Paysage:

... Les deux mains au menton, du haut de ma mansarde,

Je verrai l'atelier qui chante et qui bavarde ;

Les tuyaux, les clochers, ces mâts de la cité,

Et les grands ciels qui font rêver d'éternité.

Il est doux, à travers les brumes, de voir naître

L'étoile dans l'azur, la lampe à la fenêtre.

Les fleuves de charbon monter au firmament

Et la lune verser son pâle enchantement. Je verrai les printemps, les étés,

[les automnes ;

Et quand viendra l'hiver aux neiges monotones,

Je fermerai partout portières et volets

Pout bâtir dans la nuit mes féeriques palais.

Alors je rêverai des horizons bleuâtres,

Des jardins, des jets d'eau pleurant dans les albâtres,

Des baisers, des oiseaux chantant soir et matin,

Et tout ce que l'Idylle a de plus enfantin.

Lémeute, tempêtant vainement à ma vitre, ne fera pas lever mon front de mon

[pupitre.

El topos de la ventana propone una comparación entre el cristal de la ventana y una pantalla abierta sobre la creación. La metáfora de la ventana abierta está aprovechada por toda la crítica pictórica de la época y está también muy presente en la práctica pictórica de los pintores que utilizan la ventana como 
puesto de observación y como motivo privilegiado (Balcon del pintor Manet, Fenêtres del pintor Bonnard, de Matisse y Delaunay, ventanas también del surrealista Magritte).

Emile Zola, en su texto sobre Les romanciers naturalistas, define precisamente la obra de arte como una ventana abierta hacia la creación: « toute oeuvre d'art est comme une fenêtre ouverte sur la création...», etc.

Volviendo a la poesía de Baudelaire vemos cómo el poeta nos sitúa ante un paisaje desde lo alto de una ventana. Desde allí el poeta selecciona una serie de imágenes: elementos de la ciudad, tuberías, campanarios, talleres, lámparas, carbón, ventanas, puertas y contraventanas. Por otro lado, más arriba, coloca el cielo y sus estaciones con sus estrellas, luna, nieve; junto al paisaje «real» aplica el paisaje idílico con sus fuentes y sus cantos de pájaros puesto en oposición a l'émeute, tumulto, revuelta, realidad de la sociedad agitada. Gracias a la ventana, el poeta divide el espacio y lo fragmenta en una serie de correspondencias.

El poder ver, la visibilidad, introduce también una estética de lo discontinuo de lo oculto y de lo fragmentado. Esta obsesión de la visibilidad, tan centrada en la época del realismo, se perpetúa con el descubrimiento de la fotografía. Esta aparente exactitud de la fotografía nace durante el siglo XIX, en torno a 1839 y aporta la ilusión mimética de la reproducción exacta y eterna de cualquier modelo (v. Brunet, 2000). Brunet define la fotografía como «figure de l'exactitude et (à) la photographie comme matrice "mécanique " de cette exactitude ». De hecho, muchos escritores contemporáneos van a combinar la foto con el texto o usan la metáfora de la fotografía dentro de la narración (véase O. Rolin, Bon, Alain Fleischer, Hervé Guibert, Jean-Bernard Vray, Ernaux, Modiano...).

En la obra de Patrick Modiano, en particular, encontramos frecuentes alusiones a la foto como medio de encuesta y espacio de la memoria. El imaginario literario contemporáneo introduce además la noción de eternidad vinculada a la foto; esta foto que permite fijar un momento de una vida, de un lugar y que aparentemente no se corroe ni se descompone. Sin embargo, como lo recuerda Roland Barthes con cierta ironía, la foto es vulnerable a la humedad y a la luz y finalmente empalidece y desaparece como todo lo humano:

« la photographie n'en est pas moins mortelle : comme un organisme vivant, elle naît à même les grains d'argent qui germent, elle s'épanouit un moment, puis vieillit. Attaquée par la lumière, l'humidité, elle pâlit, s'exténue, disparaît " (Barthes, 1980, pp. 145-146). 
Ante tales actitudes la mímesis se agota y la fiel reproducción de lo que se ve resulta insatisfactoria. Poco a poco el paisaje desemboca en la abstracción, eliminando lo más posible las referencialidades externas, volviéndose como el texto literario autorreferente, volcándose hacia su pictoricidad, combinando materiales, pigmentos, formas y manchas (Nicolas de Staël, Alfred Manessier, Raoul Ubac, Vieira da Silva).

Tanto en las obras plásticas como en las literarias, la relación hombre/paisaje es muy variable, desde la función decorativa del paisaje rodeando el retrato del hombre, hasta la suma preeminencia de uno en relación con el otro.

Recordemos que, a lo largo de los siglos, el ser humano ha mantenido una lucha despiadada con la naturaleza para domarla a su antojo. El control sobre la naturaleza es la historia del hombre y de su dominio sobre todas las cosas. La historia del primer hombre y de la primera mujer - Adán y Eva- castigados por Dios y alejados del paraíso, obligados a enfrentarse a una naturaleza hostil y a trabajar con el sudor de su frente es la base del vínculo simbólico entre el ser humano y su entorno. La visión bucólica de la naturaleza virgen placentera, el mito del buen salvaje propuesto por Rousseau, Paul et Virginie, Candide cultivando su jardín, son imágenes utópicas de una felicidad que pretende asociar la naturaleza a la bondad del hombre convirtiéndola en un lugar de utopía lejos de la civilización pervertida (véase el discurso de J-J Rousseau, Discours sur les sciences et les arts de 1750) tal y como queda reflejado en sus novelas L'Emile y la Nouvelle Héloise.

Pero obviamente, la relación entre el hombre y el paisaje puede ser también perturbadora. El yo atormentado del héroe romántico se enfrenta a la fuerza de la naturaleza:

« La solitude absolue, le spectacle de la nature, me plongèrent bientôt dans un état presque impossible à décrire. Sans parents, sans amis, pour ainsi dire seul sur la terre, n'ayant point encore aimé, j'étais accablé d'une surabondance de vie. Quelquefois je rougissais subitement, et je sentais couler dans mon cœur comme des ruisseaux de lave ardente; quelquefois je poussais des cris involontaires, et la nuit était également troublée de mes songes et de mes veilles. Il me manquait quelque chose pour remplir l'abîme de mon existence : je descendais dans la vallée, je m'élevais sur la montagne, appelant de toute la force de mes désirs l'idéal objet d'une flamme future...

Les sons que rendent les passions dans le vide d'un cœur solitaire, ressemblent au murmure que les vents et les eaux font entendre dans le silence d'un désert : on en jouit mais on ne peut les peindre » (Chateaubriand, 1978, p. 129).

En este fragmento Chateaubriand describe la relación entre el hombre exaltado y la naturaleza. Por otra parte muestra el cuerpo humano como mi- 
crocosmos del gran macrocosmos que le rodea - la lava ardiente que fluye, el murmullo de los vientos asociado al sonido de las pasiones... El hombre forma parte de la naturaleza y la naturaleza es parte de su organismo más íntimo. La maldición del ser humano tiene como eco la maldición de la tierra sacudida por el azote de las plagas y de las catástrofes naturales.

\section{OTRO PAISAJE: LA CIUDAD}

Según el etnólogo francés Marc Augé, la ciudad moderna es esencialmente novelesca y está siempre asociada a grandes obras literarias. En su conocido ensayo «La ciudad entre lo imaginario y la ficción», el etnólogo francés estudia los intercambios que se producen entre el escritor y la ciudad, hasta tal punto que el lector ve las ciudades «a través de aquellos que las han amado y descrito» (Augé, 1998, p.109).

El enigma de la ciudad y su fascinante diálogo con el hombre han sido insistentemente analizados. En Francia, especialistas como Henri Lefebvre o Françoise Choay, Michel Foucault, Jean Baudrillard han planteado aspectos diferentes partiendo de lecturas plurales. Su cosmopolitismo, su relación con el capitalismo como entidad demográfico-geográfica, su legibilidad, son aspectos especialmente relevantes inscritos en los estudios de la postmodernidad.

Así como pueden resultar ambiguos los valores «naturales» de la naturaleza (campo, mar, montaña, etc.) queda ineludible e irrefutable asociar la ciudad a la voluntad y a la mano del hombre. La ciudad es desde el punto de vista semiótico, un signo que hay que interpretar desde la literatura, el dibujo, la pintura o la fotografía. Existen ciudades que participan de un mundo onírico que hay que desvelar. Existen otras que claramente pertenecen al imaginario colectivo y que se igualan a un texto en el que cada uno aporta unas palabras y unos matices nuevos. Patrick Modiano es uno de los grandes escritores del París contemporáneo, pero cada lector es capaz de connotar su visión. Ya lo decía Roland Barthes, la ciudad no tiene una sola lectura y no es una única realidad geográfica objetiva y descriptiva. La ciudad cambia según quien la recorra y la viva. Un argentino por Buenos Aires no percibe lo mismo que un turista cualquiera. El París de Balzac no es el de Zola; un lector de Walter Benjamin no paseará del mismo modo por los pasajes de París como otro más ignorante o ingenuo.

La mirada varía también según el medio utilizado, plasticidad y escritura. Los cineastas buscan la polisemia de la ciudad aprovechando los sonidos y ruidos, los colores y las luces. La Roma de Fellini, el Manhattan de Woody 
Allen, o el París de Godard favorecen las metáforas del espacio a través de la imagen y de la memoria.

Los aspectos ideológicos influyen esencialmente en la mirada y la estética. La revolución industrial produce nuevos cambios en los espacios urbanos y añade nuevas coordenadas. Las grandes urbes sagradas, las ciudades símbolo de poder y riqueza de las cortes e imperios son centros sagrados de una u otra forma. Viena imperial o Jerusalén, centro místico de peregrinación, son ejemplos del papel simbólico de la ciudad.

Al cambiar radicalmente la sociedad, después de la Revolución, las grandes urbes se convierten esencialmente en centros profanos en los que una nueva clase - la burguesía - redistribuye los centros de interés. Los bancos, el comercio, grande y pequeño, los talleres y fábricas ocupan lugares nuevos. Los arrabales se pueblan con una nueva clase proletaria y los centros religiosos se descentran simbólicamente. Se imponen nuevos criterios económicos que favorecen un nuevo reparto del espacio. La ciudad de París cambia con el barón Haussmann, quien redistribuye el centro de la ciudad, abre grandes bulevares, instala el alumbrado y el alcantarillado. La reforma de la ciudad es entonces implacable y desplaza la población más pobre fuera del centro. No olvidemos que en 1846 la tercera parte de la población es obrera. El matadero central se situaba entonces en el centro de la ciudad y no había agua potable, lo que favorecía las epidemias de cólera; la transitabilidad era escasa y los espacios verdes muy reducidos. Además de las mejoras a las que ya aludimos, Haussmann construyó más de 60 kilómetros de vías públicas, transporta agua del valle del Dhuis, construye monumentos y estaciones de ferrocarriles, mejora los parques que ya existen y crea otros nuevos siguiendo el ejemplo de la jardinería inglesa. La ciudad cambia de prisa y sus modificaciones son imparables. Dice Baudelaire: « Le vieux Paris n'est plus / la forme d'une ville / Change plus vite hélas / Que le cœur d'un mortel » (Le Cygne, 1860). Y Balzac en Ferragus escribe:

" Paris est toujours cette monstrueuse merveille, étonnant assemblage de mouvements, de machines et pensées, la ville aux cent mille romans, la tête du monde » (Balzac, 1976, p. 795).

Los cambios en la capital, el uso de nuevos materiales como el hierro y el cristal, descritos por Walter Benjamin en Paris, capitale du XIX ${ }^{o}$ siècle, la nueva disposición de los espacios influye considerablemente en los pintores.

El paisaje urbano, como los demás, experimenta un proceso de progresiva interiorización del espacio recorrido o leído. La ciudad se convierte en lenguaje y en imágenes, gracias al paseante y al viajero inspirado. La ciudad, 
mucho más que el espacio natural, es una continua provocación por la intencionalidad que la caracteriza. Le Corbusier comprendió cómo una ciudad se apodera de la naturaleza y la cambia, colocando edificios representativos, calles y parques, barrios ricos y pobres, lugares de memoria profanos y sagrados.

El nexo entre esta intencionalidad redundante y la ensoñación que se manifiesta y produce en algunos casos en una obra es el viajero, paseante, contemplador. Comenta Paul Théroux, canadiense viajero contemporáneo que «el viajero es el más codicioso de los mirones románticos». La escritura constituye un nuevo espacio donde caben los efectos de la memoria.

La ciudad y su paisaje es el espacio preferido de los escritores realista del XIX. Uno de los grandes novelistas de París es Honoré de Balzac, autor de La comedia humana. Me detendré en dos novelas que describen la ciudad como un organismo vivo: La fille aux yeux d'or y Ferragus. En la primera, publicada en 1835, la ciudad está vista como un cuerpo social formado de seis esferas representativas de seis estratos de la sociedad: los obreros los comerciantes, la pequeña burguesía, el mundo de los negocios y la alta burguesía, los artistas y finalmente los aristócratas. Allí descubrimos una mezcla entre el París real de la época y un París sur-realista que ofrece una visión muy subjetiva, poblado por una humanidad monstruosa arrastrada por las pasiones que pone en presencia el deseo y la violencia.

En la novela Ferragus Balzac incita al lector a deambular por la capital tras una mujer misteriosa. Este libro apasionó a escritores contemporáneos como Italo Calvino o Blaise Cendras; es parte de una trilogía titulada Historia de los trece.

«Hay en París ciertas calles tan deshonradas como puede estarlo un hombre culpable de infamia; hay también calles nobles, calles simplemente honestas, calles jóvenes sobre cuya moralidad el público no se ha formado todavía una opinión; calles asesinas, calles más viejas que la más vieja de las viudas viejas, calles dignas de aprecio, calles siempre limpias, calles siempre sucias, calles obreras, trabajadoras, mercantiles. Las calles de París, en fin, tienen cualidades humanas, y nos infunden con su fisonomía ciertas ideas contra las que no tenemos defensas. [...]

¡Hermoso espectáculo! Sin embargo, ¡ah, París!, quien no ha admirado tus sombríos paisajes, tus claroscuros, tus callejones profundos y silenciosos; quien no ha oído tus murmullos entre la medianoche y las dos de la madrugada, nada sabe todavía de tu verdadera poesía, ni de tus extraños y grandes contrastes» (Balzac, 2002, pp. 19-23).

París es el gran marco de la vida moderna durante el siglo XIX, sobre todo en la segunda mitad. Es fuente de inspiración para escritores, poetas y pintores. La describen como proteiforme, inquietante y grandiosa., a la medida de 
la vanidad humana, del delirio social, de la ostentación desorbitada y del individualismo radical que impera en la gran ciudad de la luz. Es también el marco de las pasiones más violentas. Balzac no se cansa de mostrarla, mientras que Zola en «Les Rougon-Macquart» la convierte en espacio de la infelicidad y del alcoholismo.

El escritor Michel Butor interpreta las armas de la ciudad y la describe como una nave a la deriva que arrastra en su naufragio todo lo que queda de la realidad.

No deja en ningún momento de ser un lugar de memoria según la expresión de Pierre Nora, testigo de las sucesivas revoluciones de 1789, 1830, 1848, 1871, descritas por Alexandre Dumas, Hugo, Zola, Jules Vallès... y Balzac siempre: Flaubert en su Education sentimentale (la de 1848), Hugo en Les Misérables mostrando la monarquía de julio, la toma de la ciudad del 2 de diciembre de 1851 en Les châtiments o las jornadas de la Comuna en Linsurgé de Vallès.

París es además un marco testigo de la historia que convierte la ciudad en un documento lo más real posible (v. Louis Sébastien Mercier autor de Tableau de Paris).

París es finalmente un espacio de memoria, tanto en su faceta histórica como en su faceta autobiográfica, como nos recuerda Philippe Lejeune en su libro La mémoire et l'oblique, a propósito del texto de Georges Pérec, Lieux.

Nuestros contemporáneos siguen el mismo camino: aludíamos a Perec; también Patrick Modiano utiliza París para reencontrarse con su propia historia, convirtiendo la ciudad en una especie de tablero de juego sobre el que el propio autor se mueve y busca una salida al recuerdo y a las obsesiones de la infancia perdida.

Recordemos también el París de las utopías o marco de ciencia ficción como en las obras de Jules Verne, autor de Paris au XX $x^{o}$ siècle, o Mercier, autor de L'an 2400. En los dos casos se describe un París ficticiamente contemporáneo pero cuyas previsiones coinciden bastante con nuestra realidad.

Finalmente tenemos un París poético, espacio de evocación e invocación, espacio mágico para surrealistas como Breton, Éluard, o Soupault.

París es además un tema privilegiado para los fotógrafos empezando por Emile Zola, Brassai y Doineau, para los dibujantes como Daumier o ToulouseLautrec, o Le Tan en la actualidad, quien publicó junto a Modiano un álbum titulado Paris de ma jeunesse.

En todos los casos, aunque desde ópticas diferentes, la ciudad se lee desde una estructura ideográfica, es decir, considerando el espacio como signo representativo de una idea. 
Para Balzac, París es mujer, mundo, volcán, infierno, monstruoso organismo. Es sobre todo algo oculto debajo de una primera capa visible. La vida secreta de París subyace en los abismos produciendo un simbolismo de doble dimensión.

Zola utiliza al igual que Balzac la ciudad de la luz en diez novelas de su ciclo de Les Rougon-Macquart y en su trilogía Trois villes. En este último caso es de gran interés la relación de Zola con los pintores de la época así como con la fotografía, que redefine la captación del paisaje urbano. El escritor busca lugares de la modernidad: la estación St Lazare, les Halles, las estructuras industriales y los andamiajes de hierro. La ciudad en la obra de Zola es uno de los personajes de sus ficciones y él mismo confiesa en su prólogo a la novela Une page d'amour que siempre soñó con escribir una novela en la que París, con su océano de tejados, fuese uno de los personajes, algo (comenta el propio autor) como el coro de la tragedia griega.

\section{PAISAJE, EXOTISMO Y LEJANÍAS: SOÑAR}

Volvamos por un momento al XIX y al paisaje redescubierto. El universo físico ya no es el mismo. Lavoisier llamó la atención sobre todo lo que se evapora, como el gas, las nubes, el aire. La pintura entonces se centra en horizontes llenos de niebla y en lejanos infinitos. El inglés Turner pinta sin separar el cielo de la tierra, lo que seguirá haciendo un siglo más tarde Nicolás de Staël en Francia. Por otra parte la velocidad entra en acción y modifica la visibilidad de los paisajes. El tren propone otra visión desde el coche: desde el asiento, el viajero ve desfilar el paisaje. El descubrimiento de la fotografía propicia también otra visión, la del panorama que tanto influyó en la disposición del cuadro.

Pero, y a pesar de todas las realidades tangibles que la ciencia y las tecnologías ofrecen, estamos en el momento del paysage-état d'âme tal y como lo llama Amiel en 1852, el diálogo empieza, las correspondencias se revelan, el espectáculo de la naturaleza está mediatizado y esta mediación se hace ver en la prosa, en la poesía y en la pintura. El desvelamiento supera la visión y la imaginación viste el paisaje y lo convierte en misterio. Los escritores realistas no dejan de lado la necesidad romántica de crear una ensoñación espacial. El exotismo, la influencia gótica de la literatura inglesa favorecen el paisaje escapista y sin duda anacrónico. El Cartago de Flaubert, el viaje a Java de Balzac, la Bohemia de Sand en Consuelo, el exotismo de Indiana, o de Nodier su Histoire du roi de Bohême et de ses sept châteaux, o incluso el París abisal de 
Eugène Sue en Les Mystères de Paris, o La fille aux yeux d'or de Balzac, o el exotismo tan pictórico de Chateaubriand en Atala (su famosa descripción del Meschacébé al inicio de la novela) o en su Itinéraire de Paris à Jérusalem son ejemplos muy puntuales que se añaden a otros muchos.

Veamos lo que dicen, empezando por Chateaubriand, que escribe en 1795 desde Londres una carta titulada «Lettre sur l'art du dessin dans les paysajes».

Recuerda Chateaubriand su niñez en plena naturaleza; conoce bien el campo, los árboles, los tipos de hojas, la botánica y sus secretos. Pone en paralelo el paisaje con el retrato y la importancia en los dos casos de lo que llama la parte moral e intelectual. Por un lado el modelo, la realidad, y el conocimiento lo más exacto posible de dicha realidad y por otra parte la sensación, la impresión pero sin caer en una visión desenfocada en busca de lo sublime y lo grande.

« Le peintre qui représente la nature humaine doit s'occuper de l'étude des passions : si l'on ne connaît le cœur de l'homme, on connaîtra mal son visage. Le paysage a sa partie morale et intellectuelle comme le portrait ; il faut qu'il parle aussi, et qu'à travers l'exécution matérielle on éprouve ou les rêveries ou les sentiments qui font naître les différents sites. Il n'est pas indifférent de peindre dans un paysage, par exemple, des chênes ou des saules : les chênes à la longue vie, durando saecula vincit, aux écorses rudes, aux bras vigoureux, à la tête altière, immota manet, inspirent sous leurs ombres des sentiments d'une tout autre espèce que ces saules au feuillage léger, qui vivent peu et qui ont la fraîcheur des ondes ou ils puisent leur sève : umbrae irrigui fontis amica salix.

$[\ldots]$

Fort alors de ses études et de son goût épuré, l'élève se livrera à son génie. Tantôt il égarera les yeux de l'amateur sous des pins où peut-être un tombeau couvert de lierre appellera en vain l'amitié ; tantôt dans un vallon étroit, entouré de rochers nus, il placera les restes d'un vieux château : à travers les crevasses des tours, on apercevra le tronc de l'arbre solitaire qui a envahi la demeure du bruit et des combats ; le perce-pierre couvrira de ses croix blanches les débris écroulés, et les capillaires tapisseront les pans de murs encore debout. Peut-être un petit pâtre gardera dans ce lieu ses chèvres, qui sauteront de ruines en ruines " (Chateaubriand, 1977, p. 274).

Chateaubriand concluye su carta volviendo a la comparación entre retrato y paisaje, insistiendo nuevamente sobre la importancia de la observación directa del modelo:

"Tout ce que j'ai voulu vous dire aujourd'hui, c'est que le paysage doit être dessiné sur le nu, si on le veut faire ressemblant, et en accuser pour ainsi dire les muscles, les os et les formes. Des études de cabinet, des copies sur des copies, 
ne remplaceront jamais un travail d'après nature. Atticae plurimam salutem » (ibíd.).

El paisaje de Chateaubriand es, como para muchos románticos, el mediador de sus sentimientos más hondos y más inestables. Renace el pasado y vuelve la memoria al oír el canto de un pájaro en los bosques de la niñez, el mismo canto de muchos años atrás; son la prueba de la fragilidad del yo y de la inalcanzable felicidad:

« le chant de l'oiseau dans les bois de Combourg m'entretenait d'une félicité que je croyais atteindre : le même chant dans le parc de Montboissier me rappelait des jours perdus à la poursuite de cette félicité insaisissable » (Chateaubriand, 1997, t. II, p. 727).

Los paisajes como los hombres desaparecen y son los testigos de los cambios que sacuden el mundo.

Benjamin Constant en su largo prólogo al drama de Schiller Wallstein se detiene en la noción central del romanticismo alemán recogida por los franceses: la de la comunión del hombre con la naturaleza y la correspondencia del alma con el paisaje:

«On dirait que des voix descendent du haut des cieux, s'élancent de la cime des rochers, retentissent dans les torrents ou dans les forêts agitées, sortent des profondeurs des abîmes. Il semble y avoir je ne sais quoi de prophétique dans le vol pesant du corbeau, dans les cris funèbres des oiseaux de nuit, dans les rugissements éloignés des bêtes sauvages. Tout ce qui n'est pas civilisé, tout ce qui n'est pas soumis à la domination artificielle de l'homme, répond à son cœur. Il n'y a que les choses u'il a façonnées pour son usage qui soient muettes, parce qu'elles sont mortes. Mais ces choses mêmes, lorsque le temps anéantit leur utilité, reprennent une vie mystique. La destruction les remet, en passant sur elles, en rapport avec la nature. Les édifices modernes se taisent mais les ruines parlent. Tout l'univers s'adresse à l'homme dans un langage ineffable... » (Constant, 1809).

Esta correspondencia con la naturaleza, esta empatía entre el hombre contemplador de la naturaleza, así como el valor del tiempo que arropa con su pátina las efímeras construcciones del hombre están expresadas en De l'Allemagne de la siguiente forma:

« La contemplation de la nature accable la pensée; on se sent avec elle des rapports qui ne tiennent ni au bien ni au mal qu'elle peut nous faire; mais son âme visible vient chercher la nôtre dans son sein et s'entretient avec nous » (Staël-Holstein, 1836, t. 2, pp. 248-249).

Paul Valéry subraya que la invasión en la literatura de la descripción coincide en pintura con la pintura de paisaje. A partir del Romanticismo, la des- 
cripción deja de ser lo que en la Enciclopedia se define como «embellissements destinés à soutenir l'attention» y se convierte en un medio para reforzar la legibilidad del texto. Opina Saint-Lambert en su Discours préliminaire a su obra Saisons:

" On doit assortir les épisodes aux paysages. Il y a de l'analogie entre nos situations, les état de notre âme, et les sites, les phénomènes, les états de la Nature » (Saint-Lambert, 1782, p. XXII).

Esta estrecha relación entre el entorno y la figura humana se extiende a todo el siglo xIx y a parte del xx. El paisaje es el espejo del yo múltiple y marco del proceso narrado (véase Batteux, Spectacle de la nature, s'Gravesende, Contemplation de la nature, Essai analytique sur les facultés de l'âme).

Charles Victor de Bonstetten en su libro L'homme du Midi et l'homme du Nord alude a una conversación cuyo contenido le revelan el valor y la importancia de la naturaleza y su relación con el pensamiento y los libros:

«Ce n'est pas aux livres, me disait-il, que la pensé s'adresse, c'est à la nature ; c'est là le libre qu'il faut lire et méditer : dans cette fleur, dans cet insecte, il y a des mystères qui, s'ils étaient révélés à l'homme, lui dévoileraient l'univers. Quelle plus grande merveille que notre pensé ; c'est là mona mi, qu'il faut porter vos regards. Les libres de philosophie ne sont que de faibles copies du grand libre que nous portons tous au dedans de nous, et qu'il faut apprendre à déchiffrer » (Bonstetten, 1992, p. 10).

Aquí está la relación entre el gran libro de la naturaleza y los libros de filosofía. La relación también entre el hombre que piensa y la naturaleza que contempla. Esta atención llevada hacia el paisaje se mantiene en el arte de Vanguardia, buscando inspiración en formas artísticas de Oriente, África y América pre-colombiana como lo recuerda el poeta Octavio Paz.

Este interés por civilizaciones y paisajes otros implica la búsqueda de otra belleza. Este cambio estético responde a un cambio radical en la visión tradicional de la realidad y sobretodo en la ruptura con la linealidad.

Esta fascinación se convierte, pero no es nueva y sirve varios propósitos. Durante el siglo XIX, el viaje, en particular entre los escritores románticos, es pretexto a todo tipo de ensoñación. Balzac no duda en inventar un viaje que titulará Voyage de París à Java y que publicará en $1832^{4}$.

Se trata de un relato de viaje en la más pura tradición romántica. El espacio y su paisaje forman parte del imaginario novelesco de aquellos años y está

\footnotetext{
${ }^{4}$ Balzac, 2006, con una interesantísima introducción de Patrick Maurus.
} 
muy de moda; encontramos alusiones a la isla de Java en la conocida novela de Eugène Sue Le juif errant y en Joseph Méry autor de Les damnés de Java de 1855 .

« Java !!! Contrée magnifique et sinistre, où les plus admirables fleurs cachent les plus hideux reptiles, ou les fruits les plus éclatants renferment des poisons subtils, où croissant des arbres splendides dont l'ombrage tue ; où le vampire, chauvesouris gigantesque, pompe le sang des victimes dont il prolonge le sommeil, en les entourant d'un aire frais et parfumé... » (Sue, 1869, p. 127).

El viaje y los lugares descritos, los paisajes lejanos exóticos, son un pretexto para el sueño voluptuoso y la reflexión sobre la realidad cercana. La representación de Oriente, los palacios de las mil y unas noches seducen a pintores y escritores, poetas y dramaturgos de la época. Oriente es el espacio de los que lo imaginan antes que el de los que realmente lo conocen.

Francia sueña con Oriente y toda la literatura y la pintura del siglo XIX reflejan esta actitud. Desde Lamartine, Gautier, Maupassant, Barrés y el extraordinario Pierre Loti, toda la belleza influenciada por una mezcla de culturas, turca, árabe, del Magreb, incluyendo los países mediterráneos como Grecia o la España del sur, invade el arte francés. Una corriente de orientalismo moderno toma el relevo en pintura con artistas como Henry Pontoy, Paul Elie Dubois o Gustave Hervigo hasta hoy.

\section{LA NOVELA URBANA Y LOS PAISAJES CONTEMPORÁNEOS; DEAMBULAR POÉTICO}

La novela urbana, ya lo comentamos, se impone con fuerza a lo largo del siglo XIX y hasta hoy. Víctor Hugo es probablemente el fundador de este tipo de novela con Notre-Dame de Paris (1831), una novela sobre la ciudad de París:

« Entre la complexité, le grouillement d'un grand roman et deux d'une grande ville, il semble qu'il y ait affinité, et que l'idée de les réunir comme la forme et la matière d'une même œuvre doive venir naturellement à l'esprit d'un romancier. Pourtant on ne trouve rien de tel avant le $\mathrm{XIX}^{\circ}$ siècle. Et il me semble bien que l'auteur de cette nouveauté féconde, le créateur du roman urbain, ce soit Victor Hugo. Je ne vois pas de précédent, avant lui... » (Thibaudet, 2007, p. 894).

La visión que ofrece Hugo, y gran parte del siglo XIX, es panorámica. Recordemos el capítulo II del libro III titulado «Paris à vol d'oiseau» en el que el escritor hace una descripción de la ciudad desde lo alto del las torres de la catedral; de forma idéntica, Michelet el historiador hace en su libro III de 
L'Histoire de France (1835) un tableau de la France contemplada desde lo alto de las montañas (los Vosgos).

La ciudad es a menudo también el actor de las novelas: Paul Bourget pone la ciudad de Roma en el centro de su libro Cosmopolis (1893), Rodenbach elige Brujas como epicentro de su novela Bruges-la-Morte (1892).

Julien Gracq publica en 1985 La forme d'une ville, dedicado a Nantes. Para él la forma de la ciudad es un juego de palabras con la horma (forma/horma), el molde que se emplea para dar forma a algo, para influir en este caso en el imaginario del poeta o escritor. El rastro de los espacios y de los paisajes determina las disposiciones del espíritu y el paisaje mental. Como él, en el mismo lugar, la misma ciudad, Rimbaud, Breton, Jacques Vaché sienten el poder de la ciudad de Nantes, este ser anfibio no del todo terrestre ni del todo marítima, lo justo — comenta Gracq - para convertirla en sirena...

Claude Simon es otro gran contemporáneo anclado en la ciudad y en la naturaleza. La ciudad de Barcelona, asociada a la guerra en su novela Le Palace. La ciudad enferma de Simon nos recuerda a menudo la ciudad enferma de Camus en La Peste, pero encontramos en Camus la capacidad de rendir homenaje a la ciudad y a sus legados:

« Mais où trouver la solitude nécessaire à la force, la longue respiration où l'esprit se rassemble et le courage se mesure ? Il reste les grandes villes. Simplement, il $\mathrm{y}$ faut des conditions.

Les villes que l'Europe nous offrent sont trop pleines des rumeurs du passé. Une oreille exercée peut y percevoir des bruits d'ailes, une palpitation d'âmes. On y sent le vertige des siècles, des révolutions, de la gloire. On s'y souvient que l'Occident s'est forgé dans les clameurs. Cela ne fait pas assez de silence.

Paris est souvent un désert pour le cœur, mais à certaines heures, du haut du Père-Lachaise, souffle un vent de révolution qui remplit soudain ce désert de drapeaux et de grandeurs vaincues " (Camus, 1954, p. 14).

Estos mismos autores - Simon, Gracq, Perec - tienen puesta una enorme vitalidad en los paisajes y en las sensaciones asociadas a su contemplación: la luz mediterránea de los paisajes camusianos, los paisajes húmedos y los bosques del campo francés que describe Gracq en sus admirables Carnets du grand chemin, las imágenes de los paisajes simonianos donde se mezclan los cuerpos descuartizados con los troncos cortados:

« Une première fois déjà, j’étais revenu à Tipasa, peu après ces années de guerre qui marquèrent pour moi la fin de la jeunesse. J'espérais, je crois, y retrouver une liberté que je ne pouvais oublier. En ce lieu, en effet, il y a plus de vingt ans, j’ai passé des matinées entières à errer parmi les ruines, à respirer les absinthes, à me 
chauffer contre les pierres, à découvrir les petites roses, vite effeuillées, qui survivent au printemps...»(Camus, 1954, p. 145).

«Ceci donc : l'humide chair blonde des jeunes arbres attaqués à la hache volante en éclats éparpillés sur la beige, puis les troncs se rompant, se déchirant, leur cassure hérissée d'échardes aiguës, s'abattant, traînés...» (Simon, 1981, pp. 119-120).

En esta descripción se destaca la irrealidad del paisaje exterior, su híbrida representación minotaura del tronco/hombre, mientras Camus y Gracq asumen el diálogo entre el entorno y el hombre que lo transita, la voluptuosidad del movimiento, del sol, del mar, esta invitación a pasear, sentir, vivir en una actitud casi siempre activa, voluntaria, reactiva, siempre presente en la gran tradición literaria francesa en autores muy diversos.

Gracq en unas interesantes páginas dedicadas a la relación entre paisaje y literatura (En lisant en écrivant) observa que en la filosofía occidental, el hombre « y est systématiquement envisagé, par rapport au monde, dans son écart maximum. Tous les états où cette tension antagoniste se relâche : sommeil, rêve, état mystiques, contemplatifs ou végétatifs, sentiment de participation ou d'identification des civilisations sauvages, ou de certaines maladies mentales, ont été par elle opiniâtrement dévalués»(Gracq, 1980, p. 9).

Esta observación es interesante porque hace hincapié en la noción de actividad y tensión del hombre frente al hombre. El hombre sin tensión, sin acción, es rápidamente un hombre sin rumbo, apático y depresivo como el héroe de Camus. La contemplación estática y feliz ante el paisaje inmóvil seduce poco e inquieta mucho al occidental en general.

La abstracción en pintura ha marcado el final del paisaje como conjunto. Pero Francia es, no lo olvidemos, un país de naturaleza, con gran variedad de paisajes. A pesar de las últimas corrientes literarias, en la literatura francesa contemporánea una recuperación de la tierra y de sus paisajes e incluso un cierto retorno a la figuración. Existen también obras ancladas en los paisajes, como la de Julien Gracq o de Philippe Jacottet con quienes concluiré mi vagabundeo entre siglos.

«... Il y a une trace d'élégance rustique et de netteté un peu distante dans ces villages plus secrets que les autres, à l'entrée desquels on s'attend malgré soi à apercevoir la haute grille d'un parc [...]

Le cyprès : intrusion sévère, violemment protestataire, de l'univers des solides parmi la folle agitation féminine, hystérique, des feuilles et des vergettes à chaque instant mises en émoi par le vent. Tout ici est refus exemplaire de la flexion. Les rameaux se referment sur le tronc comme le faisceau contreforté d'un parapluie, se soudent durement par la pointe comme les poils d'un pinceau encollé. Les fruits, minéralisés, d'une rigidité étrange de fossiles, font penser à de minuscules ballons 
de football éclatés aux coutures, mais ces segments disjoints qui provoquent l'ongle, nulle force ne peut les séparer » (Gracq, 1992, p. 10).

«Ce soir, lumière dorée dans l'air froid. Comme elle quitte vite les arbres et s'élève jusqu'aux nuages emportés par le vent. Dans le jardin, feuilles mortes de l'acacia, jaune pâle, les premières à tomber ; il y a chaque jour abondance sur le sol. Celles du plaqueminier changent avec plus d'éclat, de lenteur et de complexité, tandis que les fruits mûrissent. Le pêcher, vert encore, s'éclaircit pourtant » (Jacottet, 1984, p. 19).

Jacottet en La Semaison, como Gracq en Carnets du grand chemin, como René Char en Feuillets d'Hypnos, como Paul de Roux en Intermittences du jour, carnets 1984-1985, es autor de carnets que podemos traducir por «libretas» en las que anota brevemente, sobre la marcha, lo que ve, anotaciones impresionistas relacionadas con el paisaje y sus variaciones en función del tiempo, de la hora del día, un especie de «diario meteorológico» muy contemporáneo, basado en el fragmento, bocetos del tiempo y de sus efectos sobre la vegetación, el cielo, los colores y sus variaciones, un «retrato» (como decía Chateaubriand) preciso de la naturaleza, muy focalizado en un punto, un detalle. En la contemplación escrita del paisaje hay una lección, una reflexión filosófica, una meditación existencial en torno a la idea de la muerte, de lo visible y de lo invisible, así como una reflexión crítica y estética a partir de textos vistos desde su labor de traductor o de crítico (Chestov, Bataille, Cioran, Weil, Hölderlin, Platon, Supervielle, Castaneda... $)^{5}$.

Su obra se caracteriza por el gusto por la brevedad, la anotación, el aforismo, la aproximación a la tradición extremo oriental del haïku, también muy presente en la obra de Bonnefoy y otros grandes contemporáneos:

«A la fin de l'hiver qui nous conduit ? Parmi le bois le croissant

De la neige » (Jacottet, 1984, p. 46).

« Dans un silence absolu, une lenteur douce, irrésistible, la plante se déchire et se dissémine, confiée au vent » (Jacottet, 1984, p. 12).

\section{BREVE CONCLUSIÓN}

El paisaje no deja de renovarse en la literatura contemporánea pero está cuestionado a la par que el concepto de realidad. Las nuevas teorías científicas, el psicoanálisis, las nuevas tecnologías cambian la función de la obra de arte

5 Philippe Jacottet publicó tres volúmenes de artículos y notas de prensa titulados L'entretien des muses, Une transaction secrète, Écrits pour Papier journal. 
convertida en lo que Umberto Eco llamó la opera aperta, en continúa interacción con el espectador/lector, sometida a la visión que le otorga el espectador.

Las máquinas célibes de Marcel Duchamp, los textos de Raymond Roussel quien afirmaba que una obra de arte no tiene que contener nada real, la llegada de la abstracción en pintura con paisajes como los de Alfred Manessier (por ejemplo Les sables de la Baie de Somme) convierten en signos lo visible precario:

« Toutes choses visibles, comme des cris ou des soupirs de l'Invisible souffrant d'être invisible, comme des espèces de flammèches au-dessus ou autour d'une consomption forcenée (ou heureuse). [...] partout on lit des signes, mais l'œil qui les décèle est déjà près de se fermer, et ils restent épars, intermittents comme cris d'oiseaux avant le jour » (Jacottet, 1984, p. 74).

A pesar de la adulación contemporánea hacia las artes plásticas, en esta lucha incesante entre la palabra y la imagen, la escritura sigue siendo la propuesta de los posibles, y de las variaciones infinitas de los posibles, mientras que el cuadro, en este caso el paisaje, sobre todo el figurativo, pero también en cierta medida el paisaje abstracto, propone una factura terminada o terminal del acto creativo, un archivo parado en el tiempo.

Ya no tiene el paisaje, como en el siglo XIX, esta función de transfert que le unía al personaje de ficción contribuyendo a lo que Barthes denominó effet de réel ${ }^{6}$.

El estudio del paisaje en la ficción, en este caso en la literatura francesa, pone de manifiesto su alteridad y su inevitable metaforización variable según las épocas. El Romanticismo busca los espacios abiertos y se identifica con las perspectivas lejanas mientras que el realismo intenta delimitar el espacio. La postmodernidad cambia los parámetros espaciales. La relación dentro/fuera varía con el radical cuestionamiento de la mímesis. Concluiré con una cita del pintor Jackson Pollock:

«When I am in my painting, I'm not aware of what l'm doing. It is only after a sort of "get acquainted" period that I see what I have been about. I have no fears about making changes, destroying the image, etc., because the painting has a life of its own» (Pollock, 1947-1948, p. 79).

Recibido: 08/09/2010

Aceptado: 23/09/2010

\footnotetext{
${ }^{6}$ Vuelvo en estas conclusiones a un artículo dedicado a las «relaciones entre el paisaje y el personaje en la novela del siglo XIX», publicado en Actas del X Simposio de la Sociedad Española de Literatura General y Comparada, Universidad de Santiago de Compostela: Legen, 1996, pp. 359-366.
} 


\section{BIBLIOGRAFÍA}

Auerbach, E. (1968; 1946¹): Mimésis, la représentation de la réalité dans la littérature occidentale. París, Gallimard.

Augé, M. (1998; 19971): "La ciudad entre lo imaginario y la ficción”, en El viaje imposible. El turismo y sus imágenes. Barcelona, Gedisa, pp. 109-131.

Balzac, H. de (1976): Ferragus, en La Comédie Humaine, t. V. Paris, Gallimard "Collection de la Pléiade".

Balzac, H. de (2002): Ferragus. Barcelona, Minúscula.

Balzac, H. de (2006): Voyage de Paris à Java. París-Arles, Actes Sud.

Barthes, R. (1980): La chambre Claire. Paris, Gallimard-Cahiers du cinéma-Seuil.

Bonstetten, C. V. de (1992): L'homme du Midi et l'homme du Nord. Lausana, Editions de l'Aire.

Brunet, F. (2000): La naissance de l'idée de photographie. Paris.

Camus, A. (1954): L'Eté. París, Gallimard, "Les essais LXVIII".

Carus, C. G. (1992): Cartas y anotaciones sobre la pintura de paisaje. Madrid, Visor.

Chateaubriand, F.-R. de (1947): Journal de Jérusalem, en Les cahiers Chateaubriand. Paris, Gallimard.

Chateaubriand, F.-R. de (1977): "Lettre sur l'art du dessin dans les paysages", en Correspondance Générale (1789-1827), Paris, Gallimard, "Collection de la Pléiade", t. I.

Chateaubriand, F.-R. de (1978): René, en Atala - René - Les Aventures du dernier Abencerage. París, Gallimard "Collection Folio Classique".

Chateaubriand, F.-R. de (1997): Mémoires d'Outre-Tombe, 2 t. París, Gallimard, "Collection Quarto".

Clair, J. (1989): Méduse. París, Gallimard.

Constant, B. (1809): "Réflexions sur Wallstein", en Wallstein, tragédie en cinq actes et en vers, précédée de Quelques réflexions sur le théâtre allemand et suivie de Notes historiques. París-Ginebra, J.-J. Paschoud.

De Diego, R. (1997): Les villes de la mémoire. Québec, Humanitas.

Gombrich, E. (1989): Historia del arte. Madrid, Alianza.

Gracq, J. (1980): En lisant, en écrivant. París, José Corti.

Gracq, J. (1992): Carnets du grand chemin. París, José Corti.

Jacottet, P. (1984): La Semaison. París, Gallimard.

Legen, B. (2002): "Madame de Staël en la encrucijada de las literaturas del Norte y del Sur", en José Enrique Martínez Fernández (coord.): Estudios de literatura comparada: norte y sur, la sátira, transferencia y recepción de géneros y formas textuales. León, Servicio de Publicaciones de la Universidad de León, pp. 171-182.

Legen, B. (1996): "Relaciones entre el paisaje y el personaje en la novela del siglo XIX", en Actas del X Simposio de la Sociedad Española de Literatura General y Comparada. Santiago de Compostela, Universidad de Santiago de Compostela, pp. 359-366. 
Paz, O. (1990): "The Nobel Prize in Literature 1990". Nobelprize.org. <http://nobelprize.org/nobel_prizes/literature/laureates/1990> [25 Oct 2010].

Pollock, J. (1947-1948): "My Painting", en Possibilities, 1, pp. 78-83.

Saint-Lambert, J.-F. (1782): "Discours Préliminaire", en Les Saisons. Ámsterdam, p. XXII.

Simon, C. (1981): Les Géorgiques. París, Éditions de Minuit, 1981.

Staël-Holstein, G. (1836): De l'Allemagne, en Oeuvres complètes. París, Didot-TreuttelWurtz, vol. 2.

Stendhal (1965): La Chartreuse de Parme. Paris, GF-Flammarion, "Livre de Poche".

Strick, J. (1986): "Connaissance, classification et sympathie, les tours de paysage et la peinture de paysage au XIX ${ }^{\circ}$ siècle", Littérature, 61, pp. 17-33.

Sue, E. (1869): Le juif errant. París, Lacroix-Verboeckhoven.

Thibaudet, A. (2007): "Le roman Urbain", en Réflexions sur la littérature. París Gallimard, "Collection Quarto".

\section{RESUMEN}

Este artículo aborda los valores del paisaje tal y como aparece en la literatura francesa a partir del siglo XIX y sus conexiones con la pintura del mismo período. El paisaje campestre que nos hace descubrir los ingleses y los alemanes y el paisaje urbano que cambia radicalmente a partir de la revolución industrial, ofrecen una dimensión simbólica y social que se proyecta en el campo literario y artístico. La sociedad francesa del siglo XIX experimenta importantes cambios socio-políticos que repercuten obviamente en toda la literatura desde el Romanticismo hasta los grandes replanteamientos de la post-modernidad.

El siglo XIX es en Francia el gran siglo de la literatura; los escritores más relevantes, Chateaubriand, Stendhal, Hugo, Balzac se detienen en la contemplación del paisaje y establecen nuevas relaciones y correspondencias con la naturaleza. La recuperación de los espacios y su polisemia concierne también todo el siglo xx y el período actual. Poetas, escritores y pintores siguen integrando el paisaje en su creación. Ya lo decía Fernand Braudel, los paisajes y los espacios no son únicamente realidades del presente pero también y sobre todo supervivencias del pasado; «la terre est, comme notre peau, condamnée à conserver la trace des blessures anciennes».

PALABRAS CLAVE: literatura francesa; pintura de paisaje; siglos XIX, XX, XXI; paisaje; paisaje urbano.

\section{ABSTRACT}

This article explores the values of landscape as seen in French literature since the nineteenth century and its connexion with painting in the same period. Both, the rural landscape presented by British and German artists and urban landscapes that radically changed since the industrial revolution, offer symbolic and social dimensions that are projected on to the literary and artistic fields. Nineteenth century French society ex- 
perimented great political and sociological changes that had repercussions in literature from the Renaissance to post-modern rethinks.

The nineteenth century is the greatest period of French literature, the most relevant writers, Chateaubriand, Stendhal, Hugo, Balzac spent time in the contemplation of the landscape and created new relationships and correspondences with nature. The recovery of spaces and their polisemy also applies to the whole of the twentieth century and the current period. Poets, writers and painters continue to integrate the landscape in their creations. As Fernand Braudel once said, landscapes and spaces are not only realities of the present time but also and above all, survivors of the past; «la terre est, comme notre peau, condamnée à conserver la trace des blessures anciennes».

KEY WORDS: french literature; landscape painting; XIX, XX and XXI centuries; landscape; urban landscape.

\section{RÉSUMÉ}

Cet article aborde les valeurs attribuées au paysage telles qu'on les trouve dans la littérature française à partir du $\mathrm{XIX}^{\circ}$ siècle ainsi que les connexions qui s'établissent avec la peinture durant la même période. Le paysage champêtre que nous font découvrir les anglais et les allemands, et le paysage urbain qui change radicalement à partir de la révolution industrielle, offre une dimension symbolique et sociale qui se projette dans le champ littéraire et artistique. La société française du XIX traverse d'importants changements socio-politiques qui influencent de toute évidence la littérature à partir du Romantisme et jusqu'à la Post-Modernité.

Le XIX siècle est en France le grand siècle du roman; les écrivains les plus connus, Chateaubriand, Stendhal, Hugo, Balzac, contemplent les paysages et établissent de nouvelles relations et correspondances avec la nature. La récupération des espaces et leur polysémie concerne aussi le $\mathrm{xx}^{\mathrm{o}}$ siècle et la période actuelle. Poètes, écrivains et peintres continuent à intégrer le paysage dans leurs créations. Fernand Braudel disait déjà que les paysages et les espaces ne sont pas uniquement des réalités du présent mais aussi et surtout des survivances du passé: "La terre est, comme mnotre peau, condamnée à conserver la trace des blessures anciennes».

MoTS CLÉS: littérature française; peinture de paysage; XIX, XX, XXI siècle; paysage; paysage urbain. 